\title{
In situ stress analysis of multilayer environmental barrier coatings
}

\author{
B. J. Harder \\ Department of Materials Science and Engineering, Northwestern University, Evanston, Illinois, USA
}

J. Almer

Argonne National Laboratory, Advanced Photon Source, Argonne, Illinois, USA

K. N. Lee

Rolls-Royce Corporation, Materials, Processes, and Repair Technology, Indianapolis, Indiana, USA

\author{
K. T. Faber \\ Department of Materials Science and Engineering, Northwestern University, Evanston, Illinois, USA
}

(Received 30 September 2008; accepted 30 January 2009)

\begin{abstract}
The biaxial stress and thermal expansion of multilayer doped-aluminosilicate environmental barrier coatings were measured in situ during cooling using microfocused high-energy $X$-rays in transmission. Coating stresses during cooling from $1000{ }^{\circ} \mathrm{C}$ were measured for as-sprayed and thermally cycled samples. In the as-sprayed state, tensile stresses as high as $75 \mathrm{MPa}$ were measured in the doped-aluminosilicate topcoat at $375^{\circ} \mathrm{C}$, after which a drop in the stress occurred accompanied by through-thickness cracking of the two outermost layers. After thermally cycling the samples, the stress in the topcoat was reduced to approximately $50 \mathrm{MPa}$, and there was no drop in stress upon cooling. This stress reduction was attributed to a crystallographic phase transformation of the topcoat and the accompanying change in thermal expansion coefficient. The addition of a doped aluminosilicate to the mullite layer did not lower the stress in the topcoat, but may offer increased durability due to an increased compressive stress. (C) 2009 International Centre for Diffraction Data. [DOI: 10.1154/1.3120602]
\end{abstract}

Key words: Ceramic, coatings, in situ, stresses, transmission, multilayer

\section{INTRODUCTION}

Silicon-based ceramics, such as silicon carbide $(\mathrm{SiC})$ and silicon nitride $\left(\mathrm{Si}_{3} \mathrm{~N}_{4}\right)$, have been pursued as structural materials in gas turbine engines due to their low densities and high thermomechanical stability (Jacobson, 1993; Lee, 2000a). However, in the presence of high temperature and pressure, water vapor reacts with these materials to form volatile silicon hydroxides. This reaction leads to recession if the substrate cannot be shielded (Opila, 1999; Opila et al., 1999; Smialek et al., 1999). To protect these materials, environmental barrier coatings (EBCs) were developed. Effective coatings have low diffusivities of reactive species and remain crack-free through the component lifetime. The most common source of residual stress and crack formation in barrier coatings is coefficient of thermal expansion (CTE) mismatch between coating and substrate. CTE mismatch and thermal cycling can induce tensile or compressive stresses which may result in cracking or spallation of the EBC layers (Evans and Hutchinson, 1984; Lee, 2000b; Thouless, 1991). When the coating is compromised, subsequent exposure to the reactive environment severely reduces the lifetime of the component. Therefore, it is critical to minimize these stresses when possible.

State-of-the-art coating systems are plasma sprayed and consist of a silicon bond coat, an intermediate layer of mullite $\left(3 \mathrm{Al}_{2} \mathrm{O}_{3} \cdot 2 \mathrm{SiO}_{2}\right)$ or mullite +20 wt. \% $\mathrm{SrAl}_{2} \mathrm{Si}_{2} \mathrm{O}_{8}$ (SAS), and an EBC topcoat of $\mathrm{Ba}_{1-x} \mathrm{Sr}_{x} \mathrm{Al}_{2} \mathrm{Si}_{2} \mathrm{O}_{8}$ (BSAS). The topcoat is deposited as metastable (hexagonal) hexacelsian. This material undergoes a phase transformation to the stable celsian (monoclinic) phase upon exposure to elevated temperatures $\left(>1200^{\circ} \mathrm{C}\right)$, with an associated volume reduction of $0.5 \%$ (Hyatt and Bansal, 1996). The intermediate mullite or mullite $+20 \%$ SAS layer acts as a reaction barrier between the topcoat and the silicon bond coat (Lee, 2000b: Lee $e t$ al., 2003). The addition of the celsian SAS phase to the mullite is intended to reduce residual stress by lowering the overall CTE of the layer. These EBC systems have proven to be effective barriers for exposures over $14000 \mathrm{~h}$ at $1200{ }^{\circ} \mathrm{C}$ in field tests (Kimmel et al., 2002).

Previous investigations have utilized high-energy syn chrotron radiation to investigate phase-specinc (and thus layer-specific) stresses using unit cell dimensions as a built-in strain gauge (Almer et al., 2003; Faber et al., 2007: Weyant et al., 2005). The goal of this work is to determine the stress evolution in multilayer coatings during cooling from $1000{ }^{\circ} \mathrm{C}$ in both the as-sprayed condition as well as after thermal cycling.

\section{EXPERIMENTAL PROCEDURES}

Multilayer doped-aluminosilicate coatings were depos ited by atmospheric plasma spray onto melt-infiltrated $\mathrm{SiC}$ $\mathrm{SiC}$ ceramic matrix composite coupons. Details of the porcessing of these coatings can be found in previous publications (Faber et al., 2007; Lee et al., 1995). The thickness of the Si layer was $\sim 130 \mu \mathrm{m}$ and the mullite, mullite $+20 \%$ SAS and BSAS layers were each $\sim 200 \mu \mathrm{m}$. The final dimensions of the samples were $2-3 \mathrm{~mm} \times 2.5 \mathrm{~mm}$ $\times 5 \mathrm{~mm}$. Samples that underwent thermal cycling were $\mathrm{er}$ posed to an atmosphere of $90 \% \mathrm{H}_{2} \mathrm{O}$-balance $\mathrm{O}_{2}$, flowing at $2.2 \mathrm{~cm} \mathrm{~s}^{-1}$ at 1 atm total pressure. In this atmospher samples were heated from room temperature to $1300^{\circ} \mathrm{C}$. held for $1 \mathrm{~h}$, cooled to $25^{\circ} \mathrm{C}$ and held for $0.25 \mathrm{~h}$; this was repeated a total of 100 times. Thermally cycled EBCs wert 


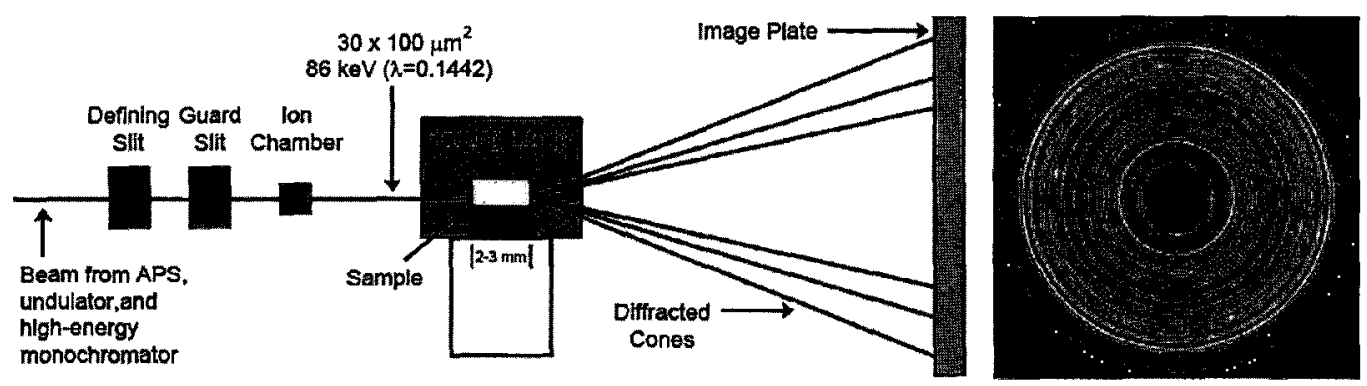

Figure 1. (Color online) Schematic for the transmission X-ray experiments with in situ heating. Inset: An example of a mullite diffraction pattern recorded on an image plate.

first annealed in air at $1300^{\circ} \mathrm{C}$ for $20 \mathrm{~h}$ in order to stabilize the topcoat. X-ray diffraction (XRD) using high-energy synchrotron radiation was conducted at the 1-ID beam line of the Advanced Photon Source at Argonne National Laboratory. The general setup for the experiments is shown in Figure 1 . High brilliance, high energy $(86 \mathrm{keV}) \mathrm{X}$-rays were produced by a Laue monochromator and were vertically focused using Si refractive lenses. A Mar345 image plate (345 $\mathrm{mm}$ diameter, $150 \mu \mathrm{m}$ pixel size) was set at a distance of $\sim 1.2 \mathrm{~m}$ from the sample, and a $\mathrm{CeO}_{2}$ standard was used to determine the sample-to-detector distance, beam tilt, and beam center. The X-ray beam size was $30 \mu \mathrm{m} \times 100 \mu \mathrm{m}$, and during each exposure the sample was translated horizontally $2 \mathrm{~mm}$ to increase the number of diffracted grains, resulting in a diffracted volume of $120-180 \mu \mathrm{m}^{3}$. Stress measurements for the coating layers are reported from the center of each layer, except in the case of the $\mathrm{SiC} / \mathrm{SiC}$ substrate, where it is reported from $100-150 \mu \mathrm{m}$ below the $\mathrm{Si} /(\mathrm{SiC} /$ $\mathrm{SiC}$ ) interface. The sample was translated vertically with respect to the beam in $50 \mu \mathrm{m}$ steps to probe the coating layers and the substrate. No overlapping peaks were used in the evaluation. Errors in the stress measurement were computed based on statistical error from peak fitting and standard errors from the biaxial fit of lattice parameter versus azimuth.

The determination of strain from the forward-scattered diffraction rings is identical to that used in previous work (Almer et al., 2003; Faber et al., 2007; Weyant et al., 2005; Weyant $e t$ al., 2006) and will be briefly discussed here. Each diffraction ring corresponds to a specific crystallographic $h \mathrm{kl}$ plane that satisfies the Bragg condition. A small ratio of grain size to probe size and lack of texture resulted in a continuous ring. The azimuthal angle $(\eta)$ designates the orientation of the diffracted set of planes relative to the sample. When the

TABLE I. Measured and calculated X-ray elastic constants used for determining stresses.

\begin{tabular}{lccc}
\hline \hline & & & $E_{h k l}$ \\
Material & Planes evaluated & $(\mathrm{GPa})$ & $\nu_{h k l}$ \\
\hline BSAS (Hexacelsian) & $\left(\begin{array}{llll}1 & 1 & 0\end{array}\right)$ & 129 & 0.35 \\
BSAS (Celsian) & $\left(\begin{array}{lll}1 & 1 & 2\end{array}\right)$ & 81 & 0.30 \\
Mullite & $\left(\begin{array}{llll}2 & 2 & 0\end{array}\right)$ & 145 & 0.16 \\
BSAS (Celsian) for SAS & $\left(\begin{array}{llll}0 & 4 & 1\end{array}\right)$ & 97 & 0.37 \\
Silicon & $\left(\begin{array}{lll}3 & 1 & 1\end{array}\right)$ & 187 & 0.15 \\
Silicon carbide & $\left(\begin{array}{lll}2 & 2 & 0\end{array}\right)$ & 422 & 0.17 \\
\hline \hline
\end{tabular}

coating is under equibiaxial strain, the ring will be distorted as a function of azimuth $(\eta)$ into an ellipse. Strain as a function of azimuth is determined by

$$
\varepsilon_{\eta}=\frac{r_{\eta}-r_{0}}{r_{0}}=\frac{d_{0}-d_{\eta}}{d_{0}}
$$

where $d_{o}$ and $r_{o}$ are the strain-free $d$-spacing and radius, respectively (Noyan and Cohen, 1987). The strain in the inplane direction, $\varepsilon_{11}$, corresponds to an azimuthal angle of $0^{\circ}$ and $\varepsilon_{33}$ corresponds to an azimuth of $90^{\circ}$. The axial strain components are determined from the two-dimensional detector images using equations derived by (He and Smith, 1998). The distortion is related to strain in the in-plane $\left(\varepsilon_{11}\right)$ and out-of-plane $\left(\varepsilon_{33}\right)$ directions. Assuming an equibiaxial strain state $\left(\varepsilon_{11}=\varepsilon_{22}\right)$, the equibiaxial in-plane stress $(\sigma)$ in the coating can be calculated from

$$
\sigma=\left(\frac{E}{1+\nu}\right) \varepsilon_{11}+\frac{\nu E}{(1-2 \nu)(1+\nu)}\left(2 \varepsilon_{11}+\varepsilon_{33}\right),
$$

where the modulus $(E)$ and Poisson's ratio $(\nu)$ are constants specific to the diffraction $h k l$ plane being measured (Noyan and Cohen, 1987). In order to determine these stresses, plane-specific X-ray elastic constants $(E, \nu)$ were determined by compressively loading bulk plasma-sprayed material and are shown in Table I. The constants used for celsian SAS were determined from bulk celsian BSAS, due to the similar crystal structure and mechanical properties of the materials (Hyatt and Bansal, 1996). Uniaxial compression measurements were not conducted on the $\mathrm{SiC} / \mathrm{SiC}$ substrate, so elastic constants were estimated by averaging the Reuss and Voigt models using single crystal moduli (Hellwege, 1979). The coatings were heated to $1000^{\circ} \mathrm{C}$ using infrared lamps (Research Inc. Model 5075, Eden Prairie, MN) and the stresses were measured in situ during cooling. A thermo-
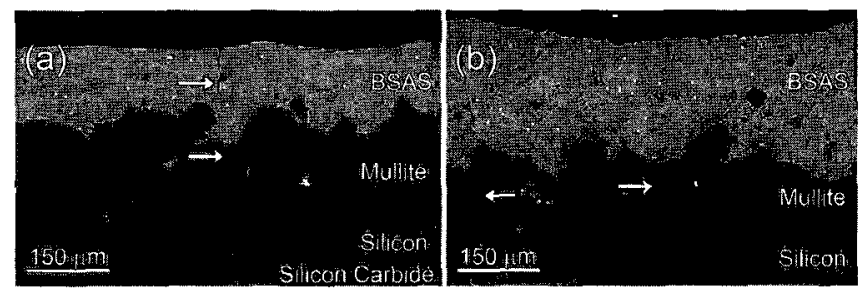

Figure 2. Backscatter electron micrographs of BSAS/mullite/Si/(SiC/SiC) after cooling from $1000^{\circ} \mathrm{C}$ in the (a) as-sprayed condition and (b) after thermal cycling. Arrows indicate vertical cracks. 
couple in contact with the sample surface acted as a feedback loop to the lamps. Residual stresses were measured in $100^{\circ} \mathrm{C}$ increments during cooling to room temperature. The sample temperature was allowed to equilibrate at each step for $\sim 10 \mathrm{~min}$. The diffraction rings used to determine residual stresses were also utilized to determine plane spacing change with temperature.

As the sample was heated, the average $d$-spacing of the $h k l$ plane increased according to the plane-specific thermal expansion coefficient. The lattice parameters at a specific temperature were determined by simultaneously solving the equations that relate $d$-spacing and lattice parameter for multiple $h k l$ planes. The change in lattice parameter was plotted as a function of temperature and a least-squares fit was used to determine the CTE. The reported values were determined from the average change of three orthogonal directions. Diffraction measurements were taken from the center of each coating layer, and the temperature of the sample was calibrated using the CTE of the silicon measured by Touloukian et al. to be modeled as a third order polynomial (Touloukian et al., 1977). The silicon bond coat was within $100^{\circ} \mathrm{C}$ of the thermocouple temperature.

\section{RESULTS AND DISCUSSION}

\section{A. Microstructure}

Cross sections of $\mathrm{BSAS} /$ mullite $/ \mathrm{Si} /(\mathrm{SiC} / \mathrm{SiC})$ coatings are shown in Figure 2. The samples were sectioned and polished after the in situ cooling stresses were measured. In the as-sprayed sample [Figure 2(a)] the BSAS topcoat was metastable hexacelsian, as verified by $1 \mathrm{D}$ diffraction patterns. The roughness of the coatings was due to the plasma-spray processing conditions and resulted in layer thicknesses varying by as much as $\pm 75 \mu \mathrm{m}$. Through-thickness cracks were observed extending from the topcoat into the mullite interlayer, but not into the silicon bond coat. The sample subjected to thermal cycling is shown in Figure 2(b). The metastable hexacelsian BSAS topcoat in this sample had fully transformed into the stable monoclinic celsian crystal structure. Unlike the as-sprayed sample, there were no cracks observed in the BSAS topcoat, although the mullite layer showed vertical cracking. The horizontal distance between cracks was greater than $500 \mu \mathrm{m}$, similar to the as-sprayed sample. Stereology indicated that porosity increased from $3 \%$ to $7 \%$ in the BSAS topcoat after transformation to the stable celsian crystal structure. It was not determined if this was due to either the incorporation of voids from cracks or the volume reduction upon phase transformation. The porosity of the mullite and silicon layers did not change after cycling and were $11 \%$ and $5 \%$, respectively. The contrast differences in

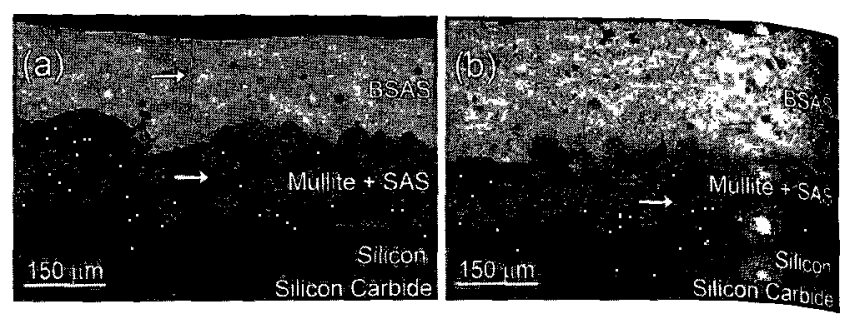

Figure 3. Backscatter electron micrographs of BSAS/mullite $+\mathrm{SAS} / \mathrm{Si} /(\mathrm{SiC} / \mathrm{SiC})$ after cooling from $1000^{\circ} \mathrm{C}$ in the (a) as-sprayed condition and (b) after thermal cycling. Arrows indicate vertical cracl.s.

the topcoat of Figure 2 (in both the as-sprayed and thermally-cycled coatings) were due to composition variations of the BSAS. The plasma-spray processing quenched the material from a melt and resulted in some phase separation upon cooling. Although compositions were not explicitly measured, energy dispersive spectroscopy (EDS) analysis determined the brighter regions had a higher $\mathrm{Ba}$ content than the darker regions.

Cross sections of BSAS/mullite $+20 \% \mathrm{SAS} / \mathrm{Si} /(\mathrm{SiC} / \mathrm{SiC})$ coatings are shown in Figure 3 . In the mullite+SAS interlayer, there was a contrast difference between the lighter SAS material and the darker mullite matrix. The inhomogeneous microstructure of this layer was a result of michanically mixing the two powders prior to spraying. Although the as-sprayed BSAS was hexacelsian, the SAS in the mullite layer in Figure 3(a) was verified via $1 D$ diffraction to be celsian. As in the sample without SAS, cracks appeared in the BSAS and mullite+SAS layers in the as-sprayed condition. After thermal cycling, the cracks in the BSAS topcoat partially sintered, but not in the mullite + SAS layer. Porosity of the layers was similar to samples without SAS.

\section{COEFFICIENT OF THERMAL EXPANSION}

The measured CTE values for the discrete coating layers between room temperature and $1000^{\circ} \mathrm{C}$ are shown in Table II. Expansion was linear with $r$-squared values of 0.97 or higher. To evaluate these coatings, measurements were compared to ground, powdered coating material. The sample temperature was calibrated using the CTE of the silicon (Touloukian et al., 1977). The CTEs of the four multilayer coating samples were in close agreement and were withis approximately $10 \%$ of the CTE of the powdered coating material. This is due to the relatively low $\left(<10^{-4}\right)$ strain within the plasma sprayed layers. Any differences between powder and layers were attributed to inconsistencies in the experi-

TABLE II. Measured coefficient of thermal expansion of multilayer coatings and ground powder. As-sprayed samples are designated "AS," and thermally cycled samples as "TC." All measurements are $\times 10^{-6}{ }^{\circ} \mathrm{C}^{-1}$. Note the samples were calibrated with the fixed silicon CTE.

\begin{tabular}{lccccc}
\hline \hline Material & AS without SAS & TC without SAS & AS with SAS & TC with SAS & Powder \\
\hline BSAS (Hexacelsian) & 8.02 & - & 8.07 & - & 8.37 \\
BSAS (Celsian) & - & 4.56 & - & 4.50 & 4.28 \\
Mullite & 6.02 & 6.04 & 5.97 & 6.06 & 5.50 \\
Silicon carbide & 4.99 & 5.17 & 5.04 & 5.21 & 5.06 \\
\hline
\end{tabular}


fore falling to zero due to crack propagation. Compressive stress in the SAS was expected, since SAS was shown to be celsian, which has a lower CTE than the surrounding mullite matrix.

However, when the sample with SAS was subjected to thermal cycling, the cooling stresses show a different profile [Figure 5(b)]. The stress magnitudes were similar to the thermally cycled sample without SAS [Figure 4(b)]. The addition of celsian SAS to the mullite layer was expected to lower the stress in the coatings by reducing the CTE mismatch of the interlayer with the other materials. This stress reduction was not observed in either the measurements or the microstructure; however, the topcoat exhibited larger compressive stresses with the addition of SAS, which is desirable for EBC applications. The increased magnitude of the compressive stress of the BSAS topcoat may increase resistance to surface cracking, improving EBC durability. This hypothesis is supported by field test results that demonstrate superior protection of samples with an alloyed interlayer (Kimmel et al., 2002).

\section{SUMMARY AND IMPLICATIONS}

The stress states in multilayer environmental barrier coatings were studied in situ during cooling from temperature using high energy synchrotron radiation. This method of high-energy X-ray diffraction in transmission allows for discrete layers to be probed and stresses to be measured. In addition to determining the biaxial stresses, the thermal expansion of discrete layers were also measured. With a high CTE nonequilibrium hexacelsian BSAS layer, large tensile stresses formed on cooling in the topcoat, resulting in fracture. A marked reduction in stress occurred at $\sim 300{ }^{\circ} \mathrm{C}$ indicating formation of these through-thickness cracks. The addition of SAS to the mullite layer in the as-sprayed state did not significantly impact the multilayer stresses. When the BSAS topcoat was in the stable celsian crystal structure, the CTE was reduced and pre-existing cracks in the topcoat healed. Cracks present in the mullite or mullite+SAS layers, however, did not close. The overall stresses in the sample with SAS were larger, contrary to expectations. The crackfree topcoat and minimal stresses of the thermally cycled samples show the most promise as environmental barrier coatings. Although samples with SAS did not exhibit lower stresses, the addition of this phase offers added durability by increasing the compressive stress of the coating layers. The stress measurements indicate that coatings with a stabilized celsian topcoat and a mullite+SAS interlayer are best suited to protect silicon-based ceramics in gas turbine environments.

\section{ACKNOWLEDGMENT}

Funding for this work was provided by the Department of Energy, Office of Basic Energy Science, under Contrad No. DE-AC02-06CH11357.

Almer, J., Lienert, U., Peng, R. L., Schlauer, C., and Oden, M. (2003), "Strain and texture analysis of coatings using high-energy $\mathrm{X}$-rays," Appl. Phys. 94, 697-702.

Bhatia, T., Eaton, H., Sun, E., Lawton, T., and Vedula, V. (2005). “ASME Turbo Expo: Power for Land, Sea, and Air," Reno, NV, pp. 253-258,

Evans, A. G. and Hutchinson, J. W. (1984). "On the mechanics of delami. nation and spalling in compressed films," Int. J. Solids Struct. 20455 466.

Faber, K. T., Weyant, C. M., Harder, B. H., Almer, J., and Lee, K. N. (2007). "Internal stresses and phase stability in multiphase enviro unen. tal barrier coatings," Int. J. Mater. Res. 98, 1188-95.

He, B. B. and Smith, K. L. (1998). "Fundamental equation of strain and stress measurement using 2D detectors," Proceedings of the 1998 SEW Spring Conference on Experimental and Applied Mechanics, Houstom $T X$, pp. 217-220.

Hellwege, K. H. (1979). Elastic, Piezoelectric, and Related Constants of Crystals (Springer-Verlag, Berlin), Vol. 11.

Hyatt, M. J. and Bansal, N. P. J. (1996). "Crystal growth kinetics in $\mathrm{BaOAl}_{2} \mathrm{O}_{3} 2 \mathrm{SiO}_{2}$ and $\mathrm{SrOAl}_{2} \mathrm{O}_{3} 2 \mathrm{SiO}_{2}$ glasses," Mater. Sci. 31, 172-184.

Jacobson, N. S. (1993). "Corrosion of silicon-based ceramics in combustion environments," J. Am. Ceram. Soc. 76, 3-28.

Kimmel, J. B., Miriyala, N., Price, J. R., More, K. L., Tortorelli, P. F., Eaton, H. E., Linsey, G. D., and Sun, E. Y. (2002). "Evaluation of CFCC liners with EBC after field testing in a gas turbine," J. Eur. Ceram. Soc. 22, 2769-2775.

Lee, K. N., Fox, D. S., Eldridge, J. I., Zhu, D. M., Robinson, R. C., Bansal, N. P., and Miller, R. A. (2003). "Upper temperature limit of environmental barrier coatings based on mullite and BSAS," J. Am. Ceran. Soc. $86,1299-1306$.

Lee, K. N. (2000a). "Current status of environmental barrier coatings for Si-based ceramics," Surf. Coat. Technol. 133-134, 1-7.

Lee, K. N. (2000b). "Key durability issues with mullite-based environmental barrier coatings for Si-based ceramics," J. Eng. Gas Turbines Power 122, 632-636.

Lee, K. N., Miller, R. A., and Jacobson, N. S. (1995). "New generation of plasma-sprayed mullite coatings on silicon carbide," J. Am. Ceram. Soc. 78, 705-710.

Noyan, I. C. and Cohen, J. B. (1987). Residual Stress: Measuremnt by Diffraction and Interpretation (Springer-Verlag, New York).

Opila, E. J. (1999). "Variation of the oxidation rate of silicon carbide with water-vapor pressure," J. Am. Ceram. Soc. 82, 1826-1834.

Opila, E. J., Smialek, J. L., Robinson, R. C., Fox, D. S., and Jacobson, N. S. (1999). " $\mathrm{SiC}$ recession caused by $\mathrm{SiO}_{2}$ scale volatility under combustion conditions: II, thermodynamics and gaseous-diffusion model," ?. Am. Ceram. Soc. 82, 1826-1834.

Smialek, J. L., Robinson, R. C., Opila, E. J., Fox, D. S., and Jacobson, N. S. (1999). "SiC and $\mathrm{Si}_{3} \mathrm{~N}_{4}$ recession due to $\mathrm{SiO}_{2}$ scale volatility under combustor conditions," Adv. Compos. Lett. 8, 33-45.

Thouless, M. D. (1991). "Cracking and delamination of coatings," J. Vac. Sci. Technol. A 9, 2510-2515.

Touloukian, Y. S., Kirby, R. K., Taylor, R. E., and Lee, T. Y. (1977). Thermal Expansion of Nonmetallic Solids (Plenum, New York), Vol. 13.

Weyant, C. M., Faber, K. T., Almer, J. D., and Guiheen, J. V. (2005). "Residual stress and microstructural evolution in tantalum oxide coatings on silicon nitride," J. Am. Ceram. Soc. 88, 2169-2176.

Weyant, C. M., Faber, K. T., Almer, J. D., and Guiheen, J. V. (2006). "Residual stress and microstructural evolution in environmental barrier coatings of tantalum oxide alloyed with aluminum oxide and lanthanum oxide," J. Am. Ceram. Soc. 89, 971-978. 